\title{
Considerações sobre a esfera pública: redes sociais na internet e participação política
}

\author{
Considerations on the public sphere: social networks \\ on the internet and political participation
}

Jackson da Silva MEDEIROS 1

\section{Resumo}

Este trabalho aborda a questão da esfera pública proposta por Habermas a partir das redes sociais na Internet e o processo de participação política proporcionado por essa forma de comunicação e informação. Faz um traçado sobre a questão, que envolve a esfera pública e opinião pública, tratando as redes sociais na Internet como um espaço de intercâmbio entre atores. Por fim, busca mostrar que as redes sociais na Internet atuam como potencializadoras de uma participação política mais efetiva, e que isso deve ser explorado de forma mais ativa.

Palavras-chave: Esfera pública. Informação na web. Participação política. Redes sociais na internet.

\begin{abstract}
The paper addresses the question of the public sphere proposed by Habermas from social networking on the Internet and the process of political participation provided by this form of communication and information. It analises the issue involving the public sphere and public opinion, dealing with social networks on the Internet as a space for exchange among actors. Finally, it attempts to show that social networks on the Internet act as enhancers of more effective political participation and that this should be more actively explored.
\end{abstract}

Keywords: Public sphere. Information on the web. Political participation. Social networks on the internet.

\section{Introdução}

O presente trabalho busca abordar, a partir da visão de Jürgen Habermas, a noção de esfera pública e opinião pública na Internet, tratando de algumas considerações sobre esses temas. A partir de breve revisão sobre os conceitos de esfera pública e opinião pública, pretende situar esses temas no contexto atual das redes sociais na Internet.

Entendendo que as redes sociais na Internet atuam como espaços de colaboração que contemplam uma estrutura capaz de subsidiar e promover a"Mediação entre os cidadãos e as ações políticas e de expressão de modos de subjetivação não identitários, em contraponto aos territórios familiares e de identificação comunitária" (Zuin, 2009, p.2), busca-se trazer à lume algumas reflexões sobre a participação política nesses espaços.

Desse modo, a partir do entendimento do conceito de "público" como proposto por Habermas (2003) isto é, quando certos eventos, em contraposição às sociedades fechadas, são acessíveis a qualquer indivíduo -, e considerando a ideia de que a Internet compreen-

\footnotetext{
1 Doutorando, Universidade Federal do Rio Grande do Sul, Faculdade de Biblioteconomia e Comunicação, Programa de Pós-Graduação em Comunicação e Informação. R. Ramiro Barcelos, 2705, Santana, 90035-007, Porto Alegre, RS, Brasil. E-mail: <jacksonmedeiros@yahoo.com.br>.

Recebido em 29/5/2012 e aceito para publicação em 29/8/2012.
} 
de um espaço público sem intermediários ou reguladores institucionais, possibilitando novas maneiras dos sujeitos conviverem, pensarem e se manifestarem. Assim, "O sujeito dessa esfera pública é o público enquanto portador da opinião pública" (Habermas, 2003, p.14).

Essa análise parte do pressuposto de que a evolução dos meios de comunicação altera a forma como os indivíduos interagem e formam opinião, bem como altera as relações entre as esferas política e civil. Parece-nos, no entanto, que os espaços de debate público na Internet ainda necessitam de uma validação, ou seja, um processo que passa pelos tradicionais meios de comunicação para efetiva atuação na esfera política.

Sem a pretensão de trazer respostas, mas, sim, vislumbrar caminhos a serem trilhados, percorre-se brevemente os conceitos de esfera pública, opinião pública e redes sociais (na Internet), visando, a partir da interlocução desses conceitos, algumas reflexões sobre o tema.

Assim, este trabalho objetiva abordar aspectos de uma possível esfera pública na Internet, cujas redes sociais potencializariam a participação política de atores que, caso não existissem os dispositivos interacionais ${ }^{2}$ e tecnológicos para debate e opinião pública, provavelmente estariam à margem da possibilidade de tratar sobre processos deliberativos.

\section{Esfera pública e opinião pública}

Adota-se aqui o conceito de esfera como um campo ou área em que se exerce alguma atividade - intelectual ou física -, sendo um campo que expande determinado poder (Houaiss, 2009). Dessa forma, pode ser compreendido como influência nesse setor, ou seja, essa esfera é uma estrutura que agrega diversos tipos de entidades que se comunicam num espaço informacional e comunicacional e que atuam em um jogo de forças para o estabelecimento de relações de poder.

Como Habermas (2003) deixa explícito no prefácio de seu trabalho "Mudança estrutural da esfera pública", a ideia de esfera pública parte de uma categoria típica de época, sendo engendrada no desenvolvimento da sociedade burguesa com início na Idade Média. Assim, está baseada na expansão do capitalismo, bem como na possibilidade de troca de informações a partir dos meios de discussão existentes na época, principalmente por meio da imprensa, criada nesse período. Em virtude de um estado de forças dominantes, como o clero e a nobreza, a sociedade burguesa buscava uma organização representativa junto às políticas da época. Com isso, o indivíduo é partícipe da esfera pública a partir da sua opinião pública, que, na visão de Habermas, advinha de interesses em comum dentro de uma esfera privada, interesses dos burgueses em relação as suas propriedades como forma de garantir a estabilidade do que lhes pertencia, necessitando de esquemas capazes de contrapor as autoridades existentes, como a nobreza e o clero. Assim, como ressalta Habermas (2003, p.110), o "Autoentendimento da função da esfera pública burguesa cristalizou-se no topos da opinião-pública".

Esse é o nascimento de uma sociedade civil burguesa no contexto da contraposição à autoridade, fazendo com que as microrrelações existentes até aquele momento, ou seja, as realizadas de forma doméstica, passassem a um espectro mais amplo, assim à luz da esfera pública. Isso posto, as atividades privadas compostas pela família e pelo trabalho necessitavam se orientar por um campo maior: o campo público (Habermas, 2003).

Um grupo de direitos fundamentais refere-se à
esfera do público pensante (liberdade de opinião
e de expressão, liberdade de imprensa, liberda-
de de reunião e de associação) e à função política
das pessoas privadas nessa esfera pública (direito
de petição, direito eleitoral e de voto igualitário
etc.) (Habermas, 2003, p.103).

É nesse ambiente notado por Habermas que se entende a necessidade de discutir dispositivos que permitam a interação entre os atores envolvidos no debate de questões políticas e que se vislumbra, a partir da atual relevância do tema, falar sobre as redes sociais na Internet como instrumentos potencializadores da esfera pública ${ }^{3}$.

\footnotetext{
2 Dispositivos interacionais "São espaços e modos de uso, não apenas caracterizados por regras institucionais ou pelas tecnologias acionadas; mas também pelas estratégias, pelo ensaio-e-erro, pelos agenciamentos táticos locais - em suma -, pelos processos específicos da experiência vivida e das práticas sociais" (Braga, 2011, p.11).

3 Pretende-se neste trabalho compreender as relações entre a proposta de esfera pública e opinião pública de Habermas (2003) a partir das potencialidades das redes sociais na Internet.
} 


\section{Redes sociais na Internet: espaço de intercâmbio}

A noção de rede, atualmente, define sistemas de relações, como redes sociais e de poder, circundando diversas áreas de conhecimento com fins variados. Seu relato inicial na literatura data do século XII na França, designando fios entrelaçados para os tecidos usados em cestas, cordeis, malhas etc. (Musso, 2010).

O termo rede passou por uma série de adaptações ao longo dos séculos, mas sua ruptura conceitual próxima do que é hoje ocorreu entre os séculos XVIII e XIX, quando passou de um estado natural para um estado artificial, ou seja, o conceito de rede começou a ser construído, uma vez que passou a ser pensado a partir de sua relação com o espaço (Musso, 2010).

Nesse contexto de relação com o espaço, com a sociedade, pode-se entender que as redes são como fios isolados que se ligam uns aos outros. Assim, é impossível compreender a rede a partir da análise de fios isolados, cabendo levar em consideração o modo como esses fios se conectam e como mantêm reciprocidade em suas relações, embora em sua individualidade possam se alterar a partir de tensões ou da estrutura interna da própria rede (Elias, 1994).

Embora, como destaca Elias (1994, p.35), essa possa ser uma imagem inadequada e rígida de um modelo de rede, ela mostra de maneira clara que uma ordem oriunda de diversas unidades não pode ser estudada de maneira individual, uma vez que está "Em constante movimento, como um tecer e destecer ininterrupto das ligações".

Dessa forma, Musso (2010, p.31) propõe uma definição de rede, que é utilizada para este trabalho: "Rede é uma estrutura de interconexão instável, composta por elementos em interação, e cuja variabilidade obedece a alguma regra de funcionamento". Os elementos de interação são os nós, os indivíduos interconectados, instáveis a partir do dinamismo próprio da rede e que obedecem a regras próprias para o seu funcionamento.

Em relação às redes sociais, pensar como as pessoas interagem, principalmente em um ambiente digital, visualizando o contexto em que isto é posto, pode ser realizado através de redes sociais na Internet.

Uma rede social é composta por dois elementos: atores, que são pessoas e/ou grupos, e conexões, ou seja, seus laços sociais, sendo estes provedores da comunicação existente entre os atores e, portanto, do emergir de grupos sociais (Recuero, 2009).

Quando uma rede de computadores conecta pessoas ou organizações, isto é uma rede social. Da mesma forma que uma rede de computadores é um conjunto de máquinas conectadas por um conjunto de cabos, uma rede social é um conjunto de pessoas (ou organizações ou outras entidades sociais) conectadas por um conjunto de relacionamentos sociais, como amizade, trabalho cooperativo ou intercâmbio de informações (Garton et al., 1997, online).

A importância das redes sociais na Internet reside na conexão dos usuários que a utilizam, e não das máquinas, sendo estas um meio de interação entre os atores. Ou seja, é, conforme Primo (2007), um processo que reside nas interações entre os envolvidos - não somente pelas mensagens trocadas e pelos interagentes -, não sendo permitido o isolamento das partes que compõem esse sistema. Sua construção é coletiva e não é predeterminada. Trata-se de um processo emergente que mantém sua existência através de interações entre os envolvidos. Essa interação é desenvolvida a partir da participação dos indivíduos e "entre" (interação = ação entre) eles.

As redes sociais na Internet permitem que, a partir da análise dessas interações, seja analisado:".... o problema de como as estruturas sociais surgem, de que tipo são, como são compostas através da comunicação mediada por computador e como essas interações mediadas são capazes de gerar fluxos de informações e trocas sociais que impactam essas estruturas (Recuero, 2009, p.24).

É nesse contexto que surge um público que se comunica e interage de forma ativa, participativa, mantendo características de autoorganização. Isto faz com que as redes não sejam "Apenas um conceito, mas um operador para a ação", sendo "Um trabalho de interesse público" (Musso, 2010, p.26), permitindo compreender as relações entre suas ações e suas estruturas.

"Onipresentes no meio da computação social, as redes sociais, que eram chamadas de comunidades virtuais, há alguns anos conhecem um desenvolvimento fulminante" (Lévy, 2010, p.11). São indivíduos participantes das redes sociais que mantêm as atividades de colaboração e interação na rede, sendo os "Nós principais, os cruzamentos, os comutadores da computação social, 
recolhendo, filtrando, redistribuindo, fazendo circular a informação, a influência, a opinião, a atenção e a reputação" (Lévy, 2010, p.12).

\section{Redes sociais na Internet: esfera pública na rede como forma de participação}

Embora Habermas não tivesse proposto uma teoria ajustada particularmente às novas mídias e sim às conversações públicas a partir da classe burguesa, pode- se constatar que sua teoria da esfera pública é um suporte disseminado para trabalhar o papel da mídia como guardiã da democracia e do direito do público de ser informado (Mortensen; Walker, 2002).

Quando discute a ideia de esfera pública, Habermas (2003) destaca o papel da imprensa no processo de debate público e opinião pública. Com isso, pode-se compreender que os meios de comunicação exercem um fator primordial na constituição da esfera pública: a possibilidade dos fluxos informacionais e comunicacionais alcançarem cidadãos que, em outras situações, jamais poderiam criar opinião sobre determinada demanda ou tema. Em consequência, atualmente, os variados meios de comunicação, em especial Internet, estão "Incluindo em nossas preocupações certos temas que, de outro modo, não chegariam a nosso conhecimento e, muito menos, tornar-se-iam temas de nossa agenda" (Hohlfeldt, 2010, p.193). Por isso os meios de comunicação como a Internet são capaz de fornecer informações de forma rápida, gerando uma igualmente rápida mobilização.

De fato, entendendo que a relação das pessoas com a realidade não é dada de forma direta, é mediada, a percepção que se tem da realidade é dada por "Imagens que formamos em nossa mente. Desta forma, percebemos a realidade não enquanto tal, mas sim enquanto a imaginamos" (Hohlfeldt, 2010, p.192), trazendo ao imaginário a concepção de espaços de opinião pública, mobilização e participação.

É nesse espaço que, de acordo com Scherer-Warren (2006), existe um caráter cognitivo que busca compreender as transformações sociais, reconhecendo a necessidade de um espaço de deliberação pública, como um processo de discussão e reflexão "Para uma troca de razões em público" (Maia, 2006, p.153), ou seja, 'É uma forma de governo na qual cidadãos livres e iguais (e seus representantes) justificam suas decisões, isto é oferecem razões uns aos outros que sejam mutuamente aceitáveis e acessíveis a todos, com o propósito de chegar a uma conclusão que produza vínculos entre todos no presente, mas aberta ao desafio no futuro' (Maia, 2006, p.154).

Enquanto a Internet, até alguns anos atrás, provia espaços de debates através de e-mails e listas de discussão, novas possibilidades de comunicação e informação surgem como forma de aquisição de informações e debates (Maia, 2006). Como destaca Gomes (2005a), a Internet como possibilidade de expressão permite aos cidadãos alcançar outros cidadãos, possibilitando aos interessados participar do jogo democrático através de informação política atualizada e oportunidade de interação. Essa esfera virtual pode ser uma extensão da esfera tradicional, atuando como um espaço de extensão da expressão política.

Lévy (2007), em seu livro "A inteligência coletiva: por uma antropologia do ciberespaço", avigora a questão da utilização de um espaço virtual, chamado ciberespaço, o qual é ampliado pelas redes digitais de informação e comunicação a partir do contato virtual com todos e com cada indivíduo. Nas palavras de Lévy (2007, p.11) "O atual curso dos acontecimentos converge para a constituição de um novo meio de comunicação, de pensamento e de trabalho para as sociedades humanas". Pensando dessa maneira, existe a possibilidade de raciocinar, como propõe Lévy, o que está sendo executado atualmente não apenas no âmbito da observação dos impactos na rede, mas também na possibilidade de contribuição com projetos que possibilitem compreender e, por que não, incentivar a criação de uma esfera pública virtual. Este parece ser o momento. Mas é um momento contínuo. Um momento, ainda em congruência com o pensamento de Lévy, representado pela coletividade, visando o pensar, criticar e reivindicar juntos, coletivamente. Isto ocorre a partir do momento em que há compartilhamento de conhecimento e pontos de vista, caracterizando uma inteligência coletiva que permita a transformação radical "Dos dados fundamentais da vida em sociedade" (Lévy, 2007, p.18).

É importante observar, como ressalva, que, se por um lado, há o que defende Castells (2003), uma extrapolação de tempo e espaço, sendo fundamental estar 
presente na rede e vivenciar o fluxo informacional não controlado por qualquer ator, seja uma pessoa ou instituição, por outro lado, Lessig (1999) argumenta que a ideia do ciberespaço como um lugar livre e não monitorado é completamente questionável, uma vez que o código fornecedor da arquitetura do ambiente pode ser alterado por quem o domina. Assim, a mineração de dados realizada por empresas e por governos, por exemplo, pode ser utilizada como fator de regulação, requerendo envolvimento das massas sobre a possibilidade e requerimento de expressão livre.

As esferas públicas, tanto a existente em uma sociedade física quanto virtual, atuam em caráter complementar, como compreende Moraes (2001) em seu trabalho "O ativismo digital", situando a Internet como um dos meios vitais para comunicação e informação. Como ressalta Moraes (2001, online), ela é um dos meios, uma vez que não está "Dissociada dos embates sociais concretos", sendo esta uma "Relação de confluência, de acréscimo e de sinergia entre o concreto e o virtual, resultante, de um lado, da progressiva hibridação tecnológica e, de outro, do somatório de possibilidades que nenhuma das partes, isoladamente, alcançaria".

Com essa observação, pode-se notar que a ideia do projeto proposto por Lévy é relevante, uma vez que o caminho para essa deliberação é um construto contínuo. Isso é alertado por Bruxel (2004, p.34), ao tratar sobre o percurso que ainda há de se percorrer para atingir uma sociedade democrática, afirmando que parte desses desafios estão pautados na"Configuração de um novo espaço, de uma esfera pública mundial, como pela garantia de que todos os cidadãos possam ter acesso a informações confiáveis, de forma que estejam em condições de participar do debate", ou seja, com a possibilidade de criação de uma rede de interessados no debate.

Essas redes potencializam a construção de esferas públicas, onde "Coletivos em redes e as redes de movimentos sociais também têm desempenhado um papel relevante enquanto atores de resistência e propositores de políticas sociais cidadãs" (Scherer-Warren, 2006, p.222). As redes, menos centralizadas e mais democráticas, potencializam os movimentos sociais, permitindo difusão de informação de maneira rápida e ampla, conectando iniciativas globais e locais. Essas possibilidades podem dessa maneira ser consideradas como as formas mais expressivas de articulações políticas na atualidade (Scherer-Warren, 2006).

Lévy (2010) ressalta que em relação a esse novo quadro proporcionado pelas redes sociais na Internet, a transformação ocorrida na esfera pública parece ser positiva, uma vez que afeta domínios essenciais ao cidadão e suas ações perante o Estado: capacidade de aquisição de informações, de expressão, de associação e de deliberação. Estas questões aumentam a possibilidade de "Potência do povo", como ressalta Lévy (2010, p.14), adquirindo capacidade de pressionar governos"para mais transparência, abertura e diálogo".

Pode-se, por consequência, sumarizar as vantagens democráticas proporcionadas pela Internet e suas redes sociais, baseando-nos no trabalho de Gomes (2005b), "Internet e participação política em sociedades democráticas": 1) superação dos limites de tempo e espaço para a participação política; 2) extensão e qualidade do estoque de informações online; 3) comodidade, conforto, conveniência e custo; 4) facilidade e extensão de acesso; 5) sem filtros nem controles; 6) interatividade e interação; e 7) oportunidade para vozes minoritárias ou excluídas.

Percebe-se, como contraponto, que a literatura ao referir-se à Internet como um dispositivo da participação da esfera civil nos encaminhamentos das atividades públicas, fora a opinião de entusiastas e utópicos, entende que os atos ocorridos em espaços de interação e participação na Internet necessitam se aliar a validadores, ou seja, a veículos de comunicação que legitimem um processo de reivindicação política para proporcionar visibilidade e alcance.

Dessa forma, mesmo que a visibilidade e alcance da plataforma de redes sociais necessite de validadores, é interessante notar que os movimentos reivindicatórios e democráticos são emergentes, partindo de cidadãos que constroem uma opinião pública e buscam sua participação deliberativa na esfera política do Estado.

\section{Discussão}

Compreende-se que a obra "Mudança estrutural da esfera pública" de Habermas (2003) não descreve uma situação completamente teórica, mas revela uma organização civil frágil da época, ressaltando a precária ma- 
nutenção das relações sociais interdependentes, sejam elas regidas por fatores internos ou externos à esfera pública.

Desse modo, é possível entender também, que, como menciona Gomes (2005a), existe a necessidade de "capital cultural" aos indivíduos envolvidos no debate, já que a apenas o acesso à informação política não torna o cidadão mais informado ou ativo, influindo na forma como se constituiu a definição da esfera pública. Talvez seja por esse motivo que os atores buscam, em um primeiro momento, disseminar suas opiniões a partir de pequenas redes (nichos) de concordância, para depois ressaltar suas diferenças em ambientes ainda digitais, mas que permitam evidenciar diferenças de ideias. Nesse sentido que existe a deliberação, na possibilidade de considerar as palavras, as ideias, os conceitos expostos pelos outros, mas também apresentando motivos que possam ser aceitos por outros indivíduos, criando uma possibilidade de "negociação".

Deve-se pensar no fato do "Modelo de esfera pública que exige dos cidadãos um engajamento e racionalidade constantes parece ser pouco correspondente à realidade social contemporânea" (Marques, 2006, p.183). Assim, somente atitudes capazes de promover nos indivíduos a participação social e política em assuntos relevantes, bem como a capacidade crítica, serão capazes de promover um real alavancamento do conceito de esfera pública, subsidiando o que Habermas (2003) definiu como uma das qualificações de um homem privado com acesso à esfera pública: formação educacional.

Com isso, é possível fazer com que os políticos e, pode-se dizer, os processos políticos, sejam sensíveis aos processos de agendamento, fazendo com que as mídias (e nisso se inclui a Internet) tenham importância ímpar na constituição das relações políticas e acolhimento, por parte do Estado, de reivindicações propostas (Hohfeldt,
2010). Ou seja, essa nova infraestrutura faz ressurgir uma esperança de, como menciona Gomes (2005a), uma terceira via entre a democracia representativa e a democracia direta, ou ainda, que:

[...] os espaços discursivos digitais funcionem de
modo mais adequado como ferramentas de
apoio para o aperfeiçoamento das instituições
democráticas (sem abrir mão delas), possibili-
tando, por exemplo, a criação de uma gama de
artifícios com o objetivo de fomentar a partici-
pação dos cidadãos (Marques, 2006, p.166).

\section{Considerações Finais}

O trabalho procurou contemplar a questão da opinião pública na Internet e a noção de esfera pública, como proposta por Habermas, observando estes assuntos a partir das redes sociais na Internet, como um dispositivo potencializador da interação entre atores engajados em participação política.

Nesse sentido, a interação mediada pelo computador faz com que existam atores capazes de fomentar a discussão da participação política através da rede, utilizando-se de meios descentralizadas e democráticos que alavancam movimentos sociais e contribuem para disseminação de opiniões e informações que permitam ligar ideias e ideais globais e locais.

Por fim, essa é uma visão que apresenta, com certeza, um agente inspirador (e talvez, uma possibilidade de ousar, utópico, mas também é um projeto de concretude. Não obstante, cabe a cada indivíduo promover, através das redes sociais na Internet, a possibilidade de resgatar uma cidadania rompida entre a esfera política, representada e com poder de decisão, e uma esfera civil, além de propor investigações sobre até que ponto há alcance efetivo de proposições defendidas nos debates gestados nesta esfera.

\section{Referências}

BRAGA, J.L. Dispositivos interacionais. In: ENCONTRO ANUAL DA ASSOCIAÇÃO NACIONAL DE PROGRAMAS DE PÓS-GRADUAÇÃO EM COMUNICAÇÃO, 20., 2011, Porto Alegre. Anais... Porto Alegre: COMPÓS, 2011. Disponível em: <http:// www.compos.org.br/data/biblioteca_1657.doc $>$. Acesso em: 17 jun. 2011.

BRUXEL, L. Esfera pública e informação: novos desafios para a cidadania. Revista de Estudos de Comunicação, v.5, n.9, p.27-34, 2004.

CASTELLS, M. A galáxia da internet. Rio de Janeiro: Jorge Zahar, 2003.

TransInformação, Campinas, 25(1):27-33, jan./abr., 2013 
ELIAS, N. A sociedade dos indivíduos. Rio de Janeiro: Jorge Zahar, 1994.

GARTON, L.; HARTHORNTHWAITE, C.; WELLMAN, B. Studying online social networks. Journal of Computer Mediated Communication, v.3, n.1, 1997. Available from: <http:// jcmc.indiana.edu/vol3/issue1/garton.html>. Cited: 7 Dec. 2009.

GOMES, W. A democracia digital e o problema da participação civil na decisão política. Revista Fronteiras, v.7, n.3, p.214-222, 2005a.

GOMES, W. Internet e participação política em sociedades democráticas. Revista FAMECOS, n.27, p.58-78, 2005b.

HABERMAS, J. Mudança estrutural na esfera pública: investigações quanto a uma categoria da sociedade burguesa. 2.ed. Rio de Janeiro: Tempo Brasileiro, 2003.

HOHLFELDT, A. Hipóteses contemporâneas de pesquisa em comunicação. In: HOHLFELDT, A.; MARTINO, L.C.; FRANÇA, V.V. Teorias da comunicação: conceitos, escolas e tendências. 9.ed. Petrópolis: Vozes, 2010. p.187-240.

HOUAISS, A. (Ed.). Houaiss eletrônico: dicionário eletrônico Houaiss da língua portuguesa. Rio de Janeiro: Objetiva, 2009.

LESSIG, L. Code and other laws of cyberspace. New York: Basic Books, 1999.

LÉVY, P. A inteligência coletiva: por uma antropologia do ciberespaço. 5.ed. Rio de Janeiro: Loyola, 2007.

LÉVY, P. A mutação inacabada da esfera pública. In: LEMOS, A.; LÉVY,P. O futuro da internet: em direção a uma ciberdemocracia planetária. São Paulo: Paulus, 2010. p.9-20.

MAIA, R. Mídia e deliberação: atores críticos e o uso público da razão. In: MAIA, R.; CASTRO, M.C.P.S. Mídia, esfera pública e identidades coletivas. Belo Horizonte: UFMG, 2006. p.153-180.
MARQUES, F.P.J.A. Debates políticos na internet: a perspectiva da conversação civil. Opinião pública, v.12, n.1, p.164-187, 2006.

MORAES, D. O ativismo digital. Biblioteca online de ciências da comunicação. 2001. Disponível em: <http://www.bocc.ubi.pt/ pag/moraes-denis-ativismo-digital.html>. Acesso em: 30 abr. 2011.

MORTENSEN, T.; WALKER, J. Blogging thoughts: personal publication as an online research tool. In: MORRISON, A. (Ed.). Researching Icts in context. Oslo: InterMedia, 2002. p.249-279. Available from: <http://www.intermedia.uio.no/konferanser/ skikt-02/docs/Researching_ICTs_in_context-Ch11Mortensen-Walker.pdf>. Cited: 19 Apr. 2011.

MUSSO, P. A filosofia da rede. In: PARENTE, A. (Org.). Tramas da rede: novas dimensões filosóficas, estéticas e políticas da comunicação. 2.ed. Porto Alegre: Sulina, 2010. p.17-38.

PRIMO, A. O aspecto relacional das interações na web 2.0. E-Compós, v.9, p.1-21, 2007. Disponível em: <http://www. compos.org.br/seer/index.php/e-compos/article/download/ 153/154>. Acesso em: 14 maio 2011.

RECUERO, R. Redes sociais na internet. Porto Alegre: Sulina, 2009.

SCHERER-WARREN, I. Redes sociais na sociedade da informação. In: MAIA, R.; CASTRO, M.C.P.S. (Org.). Mídia, esfera pública e identidades coletivas. Belo Horizonte: UFMG, 2006. p.216-227.

ZUIN, A. Rede social, política e mídia: da esfera pública à esfera privada na internet. In: SIMPÓSIO NACIONAL ABCIBER, 3., 2009, São Paulo. Anais... São Paulo: ESPM, 2009. Disponível em: <http://www.abciber.com.br/simposio2009/trabalhos/ anais/pdf/artigos/1_redes/eixo1_art4.pdf>. Acesso em: 2 jun. 2011. 
